\title{
Electric Transfer of Ions of Alloying Elements in Aluminum Alloys by Magnetohydrodynamic Melt Processing
}

\author{
Anatoly B. Laptev ${ }^{a}$, Mikhail V. Pervukhin*b, \\ Alexandr N. Afanasiev-Khodykin ${ }^{a}$, Viktor N. Timofeev ${ }^{b}$, \\ Dmitry A. Movenko and Igor A. Galushka ${ }^{a}$ \\ ${ }^{a}$ All-Russian Research Institute of Aviation Materials \\ 17 Radio Str., Moscow, 105005, Russia \\ ${ }^{b}$ Siberian Federal University \\ 79 Svobodny, Krasnoyarsk, 660041, Russia
}

In the framework of the project 16-43-242013 $p \_$opu_м «Effect of induced electric field on the ions of hydrogen in molten aluminum alloy», with the support of FBU «Russian Foundation for basic research» of the Krasnoyarsk Krai government, Regional state Autonomous institution "Krasnoyarsk regional Fund of support of scientific and scientific-technical activities» developed a method magnetohydrodynamically treatment (MHDT) aluminum melts. Conducted studies have shown that induced in the molten aluminum alloy $1417 \mathrm{M}$ electric field changes the concentration of alloying elements in the direction of the electric field. MHDT allows you to change the average value of the concentration of alloying elements such as cerium and lanthanum by the width of the ingot 8 and $13 \%$, respectively. On the basis of the theory of MHDT on the movement induced in the electric field of charged particles, it can be argued that in the experimental conditions (temperature $700{ }^{\circ} \mathrm{C}$, cooling time $3 \mathrm{~min}$ ) in aluminum alloy $1417 \mathrm{M}$ there is a partial ionization of metal atoms, which allows to move them in the direction of the vector of the electric field. MHDT, can significantly reduce the energy consumption in the processes of electric transfer elements in aluminum alloys. Conducted successful testing of a new method of processing of metal alloys, those electrical transfer elements inside of the alloy and does not require the introduction of electrodes into the melt and installations high voltage installations.

Keywords: aluminum alloys, MHD treatment, electric transfer elements, cerium, lanthanum.

Citation:Laptev A.B., Pervukhin M.V., Afanasiev-Khodykin A.N., Timofeev V.N., Movenko D.A., Galushka I.A. Electric transfer of ions of alloying elements in aluminum alloys by magnetohydrodynamic melt processing, J. Sib. Fed. Univ. Eng. technol., 2017, 10(8), 1031-1041. DOI: 10.17516/1999-494X-2017-10-8-1031-1041.

(C) Siberian Federal University. All rights reserved

* Corresponding author E-mail address: pmv_75@mail.ru 


\title{
Электроперенос ионов легирующих элементов
}

\author{
в алюминиевых сплавах
}

магнитогидродинамической обработкой расплава

\author{
А.Б. Лаптев \\ В.Н. Тимофеев ${ }^{\tilde{\sigma}}$, Д.А. Мовенко ${ }^{\mathrm{a}}$, И.А. Галушка ${ }^{\mathrm{a}}$ \\ ${ }^{a}$ Всероссийский научно-исследовательский \\ институт авиационных материалов \\ Россия, 105005, Москва, ул. Радио, 17 \\ ${ }^{6}$ Сибирский федеральный университет \\ Россия, 660041, Красноярск, пр. Свободный, 79
}

\begin{abstract}
В рамках реализации проекта 16-43-242013 р_офи_м «Влияние индуцируемого электрического поля на ионы водорода в расплаве алюминиевого сплава» при поддержке ФБУ «Российский фонд фундаментальных исследований», правительства Красноярского края, Краевого государственного автономного учреждения «Красноярский краевой фонд поддержки научной и научно-технической деятельности» разработан метод магнитногидродинамической обработки (МГДО) алюминиевых расплавов. Проведенными исследованиями показано, что индуичруемое в расплаве алюминиевого сплава 1417 электрическое поле изменяет концентрацию легирующих добавок в направлении вектора электрического поля. МГДО позволяет изменить среднее значение концентрации таких легирующих элементов, как иерий и лантан, по ширине слитка на 8 и $13 \%$ соответственно. На основании теории МГДО о перемещчении в индуциируемом электрическом поле заряженных частиц можно утверждать, что в условиях эксперимента (температура $700{ }^{\circ} \mathrm{C}$, время охлаждения 3 мин) в алюминиевом сплаве 1417М происходит частичная ионизация атомов металлов, что позволяет перемещзать их в направлении вектора электрического поля. МГДО дает возможность значительно снизить энергозатраты при осуществлении процессов электропереноса в алюминиевых сплавах. Проведена успешная апробация нового метода обработки металлических сплавов, осуществляющего электроперенос элементов внутри сплава и не требующего внедрения электродов в расплав и сооружения высоковольтных установок ${ }^{1}$.
\end{abstract}

Ключевыеслова: алюминиевыесплавы,магнитогидродинамическаяобработка, электроперенос, иерий, лантан.

\section{Введение}

В последние годы в области литейного производства активно ведутся исследования по разработке таких физических методов, которые позволяют воздействовать на металл в момент формирования структуры, дают возможность управлять процессом кристаллизации металлов и сплавов, получать отливки с новым набором служебных свойств [1-2, 3]. Одним из таких методов воздействия на кристаллизующийся расплав является метод токового воздействия. Полученные теоретические и практические результаты авторов $[4-5,6]$ свидетельствуют о том, что под воздействием на расплав постоянного электрического тока существует возможность перемещения легирующих элементов из тела отливки к ее поверхности. Однако стройной об-

\footnotetext{
Работа выполнена в рамках реализации стратегического направления 18. Климатические испытания для обеспечения безопасности и защиты от коррозии, старения и биоповреждений материалов, конструкций и сложных технических систем в природных средах («Стратегические направления развития материалов и технологий их переработки на период до 2030 года»).
} 
щепризнанной теории токового воздействия на расплав пока нет. К настоящему времени практически неизученными остаются вопросы о токовом влиянии на механизмы фазообразования в жидко-твердых состояниях с различным типом проводимости твердых включений. Особенно много противоречий высказывается в отношении механизма массопереноса элементов во внутренних слоях отливки под действием постоянного тока. Из-за недостаточно полной теоретической и технологической разработки способа токового воздействия на кристаллизующуюся отливку в литейной форме его применение весьма ограничено [7].

Различный режим пропускания электрического тока (постоянный, периодический, импульсно-периодический) может приводить к различным эффектам в металле. Постоянный ток характеризуется неизменными во времени силой, направлением и активным сопротивлением нагрузки. Воздействие на жидкий и кристаллизующийся расплав постоянным электрическим током обеспечивает электроперенос и активизирует химические превращения в расплаве между электрическими контактами, но имеет дополнительные энергозатраты, связанные с выпрямлением переменного тока. Импульсный ток характеризуется существенно нелинейным кратковременным характером протекания, который обеспечивается разрядкой накопителя электрической энергии на нагрузке. Импульсно-периодическое токовое нагружение жидкого и кристаллизующегося металла имеет определенные преимущества перед режимами постоянного и переменного тока [8]. Прежде всего это более низкие энергозатраты при одновременном уменьшении потерь на нагрев металла. Но работы по изучению механизмов и поиску оптимальных схем такой обработки пока только начаты и находятся в стадии лабораторных исследований, а их результаты еще нельзя применить в реальных условиях литейного производства.

\section{Постановка задачи}

C помощью приложения токового воздействия на кристаллизующийся металлический расплав можно решать и обратную задачу - снижение нежелательных химических элементов и соединений в рабочих слоях изделия и их перемещение в «нерабочие» зоны.

Вопросами электропереноса (ЭП) в жидких металлах исследователи начали заниматься с 40-х гг. прошлого века. Особый вклад в развитие теоретических основ электропереноса в расплавах внесли С.И. Дракин, Д.К. Белащенко, В.А. Михайлов, П.П. Кузьменко, К. Шварц, Ц. Вагнер и др. [9, 10].

Во всех предлагаемых гипотезах (теориях) происходящие процессы рассматриваются по аналогии с движением ионов в электролитах. Эффективные заряды ионов фигурируют в теории диссоциации электролитов и в этих теориях, описывающих явление электролиза, вводится число Фарадея $\mathrm{F}=96500$, равное числу перенесенных эквивалентов заряда. Частично учитывая данные теории, Вагнер [11] пришел к окончательной формуле вида:

$$
\frac{\mathrm{t}_{2}}{\mathrm{~N}_{2}}=\frac{96500}{300} \cdot \frac{\mathrm{z}_{2} \mathrm{D}_{2}-\mathrm{z}_{1} \mathrm{D}_{1}}{\mathrm{x}} \cdot \frac{\mathrm{Ned}_{1}}{\mathrm{RTA}_{1}}
$$

где $\mathrm{t}_{2}$ - число переноса примеси; $\mathrm{N}_{2}$ - молярная масса примеси; $\mathrm{x}$ - электропроводность раствора; $\mathrm{N}$ - число Авагадро; $\mathrm{d}_{1}$ - плотность растворителя; $\mathrm{A}_{1}$ - атомная масса растворителя; $\mathrm{R}$ - газовая постоянная; е - заряд электрона; T - абсолютная температура; $\mathrm{z}_{1}$ и $\mathrm{z}_{2}$ - заряды 
атомов растворителя и примеси; $\mathrm{D}_{1}$ и $\mathrm{D}_{2}$ - коэффициенты самодиффузии ионов растворителя и диффузии переноса.

Шварц [12] ввел в теорию так называемую электрогидравлическую силу, которая по физическому смыслу идентична силе Архимеда и которая выталкивает ионы примеси из катодной области к аноду. Эпштейн и Паскин [11] считали, что к аноду должен двигаться компонент, сам обладающий в расплавленном состоянии большим электрическим сопротивлением. Качественные критерии Скауни, Эпштейна, Паскина и тем более Ангуса имеют недопустимо много исключений из общего правила, не могут правильно предсказать во многих случаях даже знак эффективного заряда. Но попытки качественного теоретического анализа электропереноса показали необходимость учета силы электрон-ионного «трения», обусловленной движущимися от катода к аноду электронами. Они определяли тесную взаимосвязь явлений электропереноса и электросопротивления, поскольку оба явления определяются одними и теми же силами электрон-ионного взаимодействия.

Объектом исследования промышленных алюминиевых сплавов в работе [9] был сплав АК12 (АЛ2, силумин), содержащий $12 \% \mathrm{Si}$. Химический состав плавок варьировался в небольших пределах (и по каждому элементу не выходил за интервалы требований ГОСТ 158393). Выбор данного сплава для исследований обосновывается следующим. Сплав АК12 обладает высокими литейными свойствами, что позволяет получать из него литые детали сложной конфигурации. Основные элементы сплава - $\mathrm{Al}$ и $\mathrm{Si}-$ не образуют химических соединений. В жидком состоянии они полностью растворены друг в друге, в твердом состоянии растворимость $\mathrm{Si}$ в $\mathrm{Al}$ резко уменьшается с понижением температуры. В температурном интервале 200-300 ${ }^{\circ} \mathrm{C}$ происходит распад твердого раствора с коагуляцией выделяющейся дисперсной фазы, что исключает в дальнейшем возможность повышения механических свойств двойных сплавов Al-Si путем термической обработки. Микроструктура таких сплавов состоит из двух фаз: $\alpha$ - твердого раствора ( $\mathrm{Si}$ в $\mathrm{Al})$ и эвтектики $\alpha+\mathrm{Si}$.

Сплав доэвтектический, находится в области первичного выделения твердого раствора $\mathrm{Al}$, в своем составе имеет малое количество легирующих элементов, что позволяет на качественном и количественном уровнях исследовать влияние постоянного электрического тока на распределение элементов между анодом и катодом в сечении отливки. Согласно плану эксперимента варьировались следующие параметры токового воздействия на расплав: плотность тока (от $3,9 \cdot 10^{4}$ до $\left.2,6 \cdot 10^{5} \mathrm{~A} / \mathrm{M}^{2}\right)$, полярность электродов.

Алюминиевые сплавы получали в лаборатории с использованием первичных шихтовых материалов: алюминий первичный марки А7 (ГОСТ 11069-2001); силумин чушковой марки АК12 (ГОСТ 1583-93); кремний марки Кр1 (ГОСТ 2169-79); лигатура Al-Fе марки ФА-60 (ТУ 14-2Р-381-2004). Режимы обработки включали изменение положения анода и катода и изменение тока - от $3,9 \cdot 10^{4} \mathrm{~A} / \mathrm{M}^{2}$ до $2,6 \cdot 10^{5} \mathrm{~A} / \mathrm{M}^{2}$. Полученные в процессе исследований обобщенные данные приведены в табл. 1 .

Однако наиболее перспективными, с точки зрения практического применения являются методы бесконтактного воздействия на расплавы металлов с целью повышения их эксплуатационных характеристик. К таким методам относится магнитогидродинамическое воздействие на электропроводящую среду (расплав металлов, электролит и др.) посредством магнитных полей. 
Таблица 1. Электроперенос в алюминиевых сплавах [9]

Table 1. Electrotransfer in aluminum alloys [9]

\begin{tabular}{|l|c|c|c|c|c|c|c|c|}
\hline \multicolumn{1}{|c|}{ Элемент } & $Z n$ & $\mathrm{Cu}$ & $F e$ & $M n$ & $T i$ & $S i$ & $A l$ & $M g$ \\
\hline \multirow{2}{*}{ Масс. \% в сплаве } & $\begin{array}{c}0,047- \\
0,071\end{array}$ & $\begin{array}{c}0,117- \\
0,171\end{array}$ & $\begin{array}{c}0,554- \\
0,719\end{array}$ & $\begin{array}{c}0,021- \\
0,024\end{array}$ & $\begin{array}{c}0,011- \\
0,012\end{array}$ & $\begin{array}{c}2,445- \\
2,660\end{array}$ & $\begin{array}{c}96,12- \\
96,47\end{array}$ & $\begin{array}{c}0,022- \\
0,046\end{array}$ \\
\hline $\mathrm{C}, \%$ & 3,4 & 10,3 & 4,8 & $-3,2$ & $-44,6$ & $-15,9$ & 0,2 & $-4,8$ \\
\hline Направление движения & $\begin{array}{c}\text { к } \\
\text { аноду }\end{array}$ & $\begin{array}{c}\text { к } \\
\text { аноду }\end{array}$ & $\begin{array}{c}\text { к } \\
\text { аноду }\end{array}$ & $\begin{array}{c}\text { к } \\
\text { катоду }\end{array}$ & $\begin{array}{c}\text { к } \\
\text { катоду }\end{array}$ & $\begin{array}{c}\text { к } \\
\text { катоду }\end{array}$ & $\begin{array}{c}\text { к } \\
\text { аноду }\end{array}$ & $\begin{array}{c}\text { к } \\
\text { катоду }\end{array}$ \\
\hline
\end{tabular}

Начало применения магнитной гидродинамики для технологического воздействия на расплавы металлов (перемешивание, транспортировка и др.) восходит к 1930-м гг. [11, 12], и основной объём работ в данном направлении производился вплоть до начала 1980-х гг. Законы магнитной гидродинамики применяются при подготовке электролитических сред для управления перемещением ионов в потоке и получения градиента их концентрации в объеме. Разработаны зависимости и программы для определения и математического расчета перемещения ионов в объеме потока электролита, направления их движения с целью достижения таких эффектов, как снижение коррозионной активности минерализованных вод, предотвращения отложения солей жесткости в трубопроводах, обеззараживания воды и пр. [13, 14].

Проведение работы [15] по перемещению ионов в растворе электролитов определило теоретическую возможность и целесообразность использования метода магнитогидродинамической обработки (МГДО) для удаления водорода и перераспределения легирующих элементов в алюминиевых сплавах.

\section{Метод решения поставленной задачи}

Суть предлагаемого метода МГДО расплава алюминия для перераспределения ионов примесей, содержащихся в обрабатываемом расплаве, можно пояснить при помощи схемы, представленной на рис. 1. Обрабатываемый объем метала 1 помещается в область действия однородного магнитного поля, создаваемого, например, системой постоянных магнитов 2, вращающихся в противоположных направлениях со скоростью v. Магниты расположены таким образом, что вектор магнитной индукции В пересекает расплав в направлении, как представлено на рис. 1. В результате этого на заряды, находящиеся в расплаве, действует сила Лоренца $\mathbf{F}$, направление которой определяется правилом левой руки:

$$
\mathbf{F}=|q| \mathbf{v B},
$$

где $q$ - величина заряда; $\mathbf{v}$ - скорость перемещения магнитного поля относительно заряда; В - вектор магнитной индукции.

Под действием силы заряженные частицы, содержащиеся в расплаве (электроны, ионы водорода и др.), придут в движение. При этом электроны (черные точки) и положительно заряженные ионы примесей (белые точки) будут двигаться в противоположных направлениях. При затвердевании расплава мы получаем градиент распределения ионов легирующих элементов в объеме металла. 


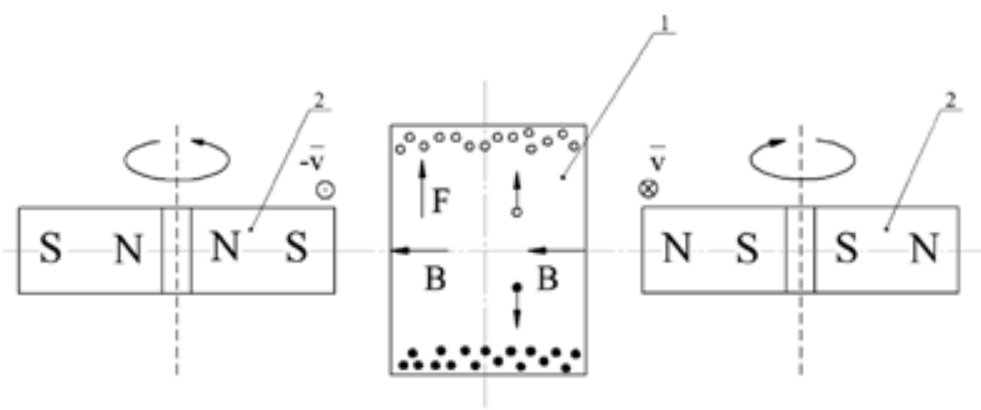

Рис. 1. Схема МГДО расплава алюминия

Fig. 1. The scheme of MHD processing of aluminum melt

\section{Методика проведения эксперимента и материалы}

Для исследования влияния магнитного поля на алюминиевые сплавы различных систем легирования был рассчитан, разработан и изготовлен стенд, включающий в себя установку индукционного нагрева ИнтерСЭЛТ и установку для проведения МГДО (аналогичную [16]) с керамической формой для получения слитков цилиндрической формы. Внешний вид установки МГДО приведен на рис. 2.

Установка имеет два вращающихся друг навстречу другу диска, соединенных между собой ременной передачей. Внутри дисков по окружности расположены магниты. Вращение дисков происходит посредством электродвигателя с максимальной скоростью вращения 1380 об/мин. Между дисками помещается тигель с расплавом. Диски имеют плавную регулировку скорости вращения от 276 до 1380 об/мин. Регулировка оборотов вращения дисков осуществляется с помощью частотного преобразователя. Между дисками устанавливалась керамическая форма для установки тигля с расплавом. Керамическая форма была дополнительно снабжена термоизоляцией, выполненной из каолинового картона, для предотвращения нагрева магнитных дисков.

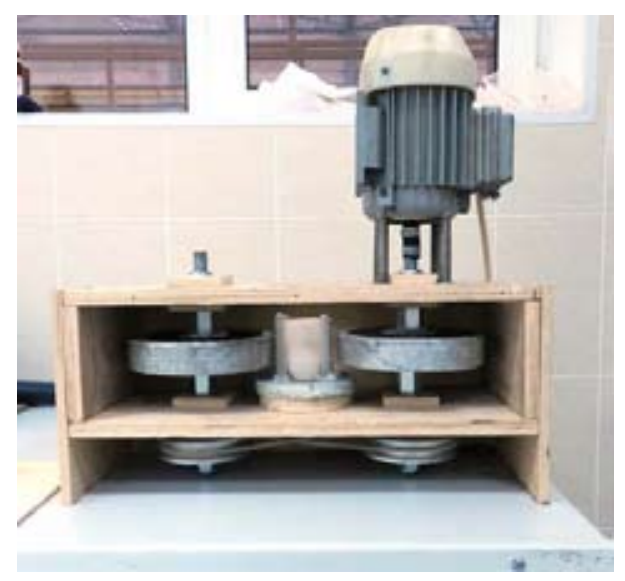

Рис. 2. Внешний вид установки МГДО расплава алюминиевых сплавов

Fig. 2. Design of MHD processing installation of aluminum alloy melts 
Шихтовые заготовки алюминиевых сплавов размером 60х20х20 мм помещали в керамический тигель внутренним диаметром 30 мм и высотой 40 мм. Расплавление шихтовой заготовки производилось токами высокой частоты на установке ИнтерСЭЛТ. Нагрев осуществлялся при помощи двух виткового индуктора при колебательной мощности установки на уровне 2-3 кВт. Рабочая частота индуктора составляла 35-36 кГц. Нагрев производился до полного расплавления шихтовой заготовки и доведения температуры расплава до $650{ }^{\circ} \mathrm{C}$. Температура расплава контролировалась при помощи пирометра. Время нагрева заготовок составляло в среднем 4-5 мин. После полного расплавления расплав перемешивался, с его поверхности удалялась окисная пленка и тигель с расплавом помещался в керамическую форму установки МГДО. Далее включался двигатель привода магнитных дисков, а скорость его вращения устанавливалась на заданном уровне. МГДО производилась до отверждения расплава. Время кристаллизации каждого слитка составляло в среднем 3 мин.

Исследования проводились на алюминиевом сплаве 1417M (3 \% La; 5,3 \% Ce; 0,015 Pr; $0,24 \mathrm{Fe} ; 0,06 \mathrm{Si})$. Кристаллизацию проводили при следующих скоростях движения магнитного поля: 2,1 м/с; 5,1 м/с и 10,3 м/с. В качестве контрольного образца сплава был изготовлен слиток без воздействия магнитного поля. В табл. 2 приведена маркировка полученных образцов.

\section{Исследование состава сплавов}

Фрактографическое исследование слитков проводили методом растровой электронной микроскопии (РЭМ) на сканирующем электроном микроскопе Tescan Vega 3 SBH, оснащенном энергодисперсионным анализатором X-Act производства Oxford Instruments. Для получения карт распределения основных химических элементов сплава была использована система анализа INCA Crystal.

После охлаждения на каждой отливке фиксировали ее положение при обработке, наносили маркировку и вынимали из кокиля. Маркировка образцов приведена в табл. 2.

Образцы распиливали по диаметральной плоскости вдоль стрелки, показывающей направление движения магнитного поля. На каждой трети образцов: «низ», «середина» и «верх» от края до края по 5 точкам поводили замеры содержания легирующих элементов La и Ce в алюминиевом сплаве 1417М. Результаты измерений приведены на графиках (рис. 3 и 4).

На рис. 3 и 4 видно, что перераспределение элементов неоднородно по ширине шлифа и имеет максимум, как правило, в средней части слитка, что может быть связано с неравномерным распределением магнитного поля и наличием граничных эффектов около стенок кокиля.

Таблица 2. Режимы проведения МГДО и маркировка образцов

Table 2. Modes of MHD processing and labeling of samples

\begin{tabular}{|c|c|c|c|c|}
\hline Марка сплава & \multicolumn{3}{|c|}{ Линейная скорость перемещения магнитного поля, м/с } \\
\hline & Без МГдО & 2,1 & 5,1 & 10,3 \\
\hline $1417 \mathrm{M}$ & 1.0 & 1.1 & 1.2 & 1.3 \\
\hline
\end{tabular}




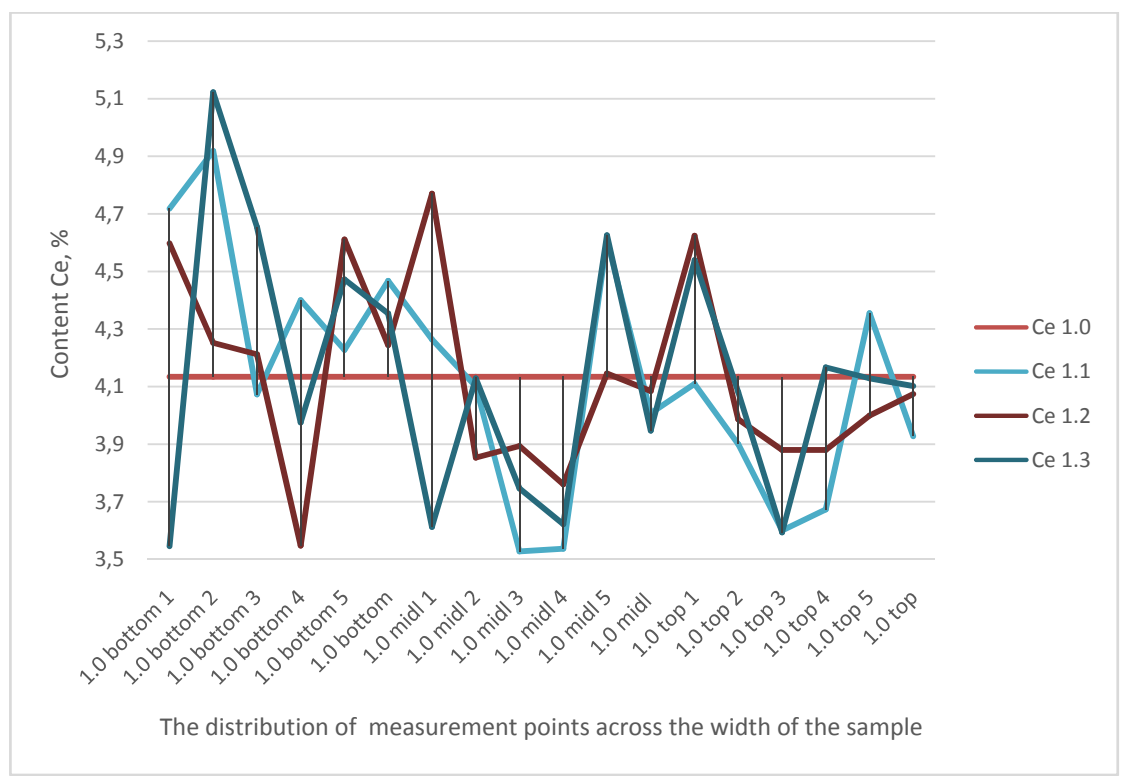

Рис. 3. Изменение концентрации церия по ширине шлифа

Fig. 3. Change of cerium concentration over the width of the section

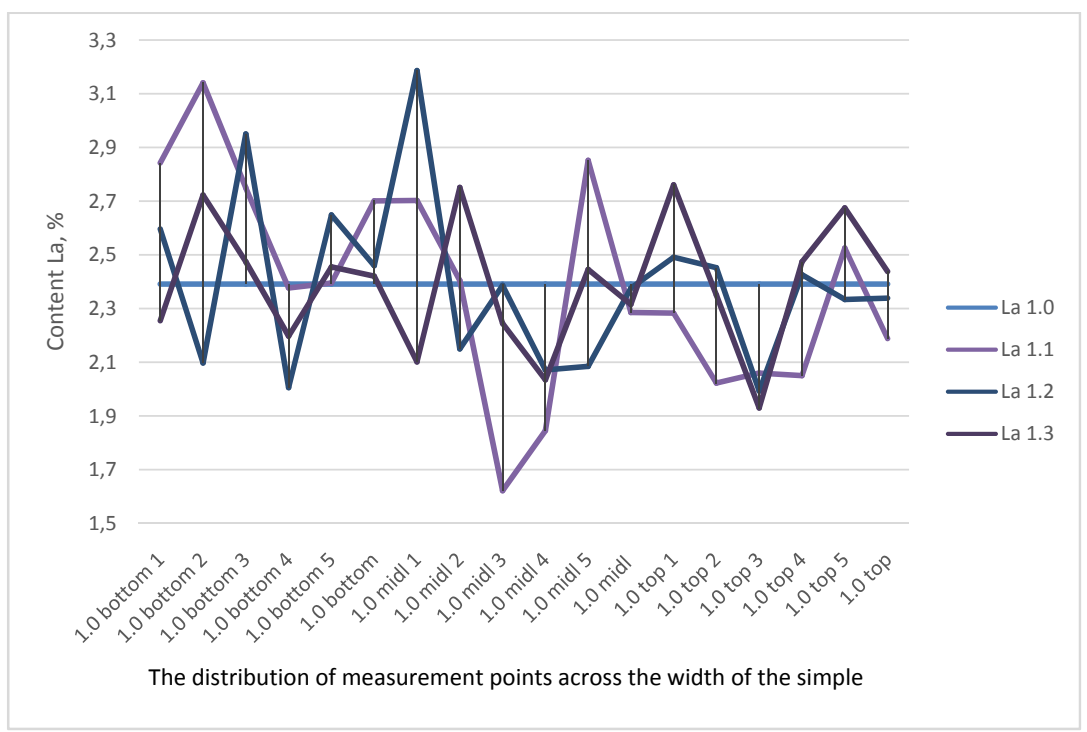

Рис. 4. Изменение концентрации лантана по ширине шлифа

Fig. 4. Change of lanthanum concentration over the width of the section

После соответствующего усреднения полученных результатов (рис. 3 и 4) выполнено построение гистограммы изменения концентрации легирующих элементов в полученных в соответствии с табл. 1 слитках. Результаты приведены на рис. 5. Мы видим, что увеличение скорости вращения магнитов не приводит к увеличению эффекта, но даже минимальная скорость позволяет изменить среднее значение концентрации элементов по ширине слитка на 8 и 13 \%. 


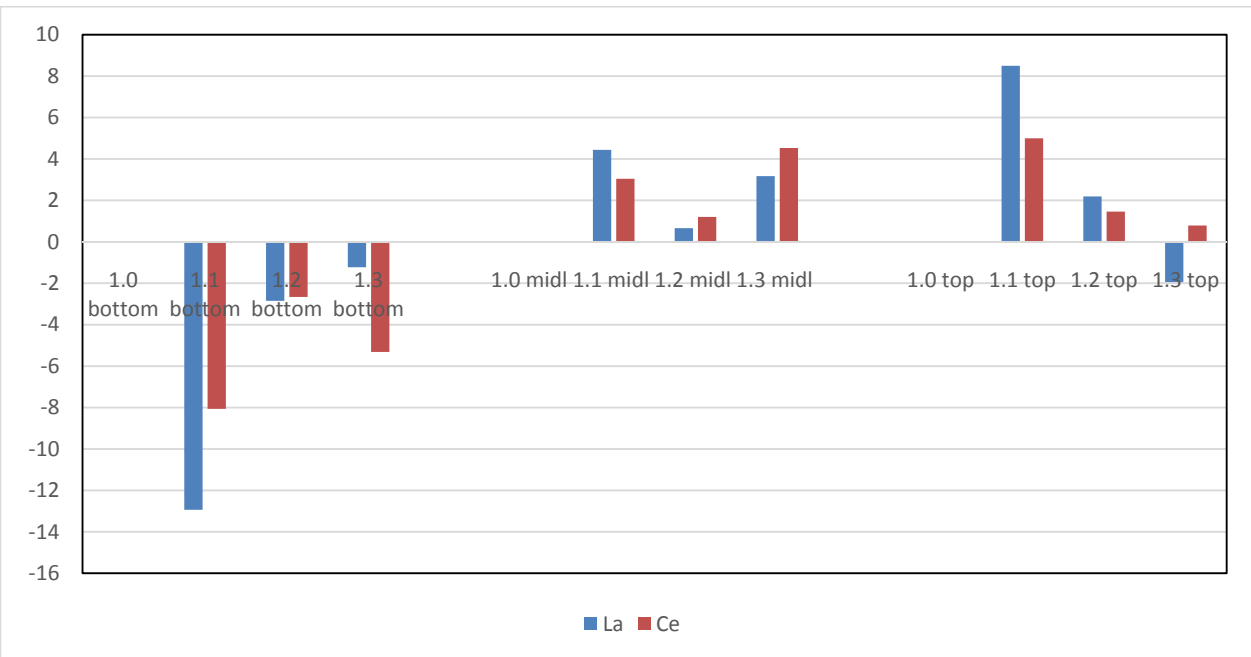

Рис. 5. Изменение концентрации легирующих элементов (\%) по высоте слитка после проведения МГДО расплава

Fig. 5. The change of the concentration of alloying elements (\%) over the height of the ingot after the MHD processing of the melt

\section{Выводы}

1. Проведенными исследованиями показано, что индуцируемое в расплаве алюминиевого сплава 1417М электрическое поле изменяет концентрацию легирующих добавок в направлении вектора электрического поля.

2. МГДО позволяет изменить среднее значение концентрации таких легирующих элементов, как церий и лантан, по ширине слитка на 8 и $13 \%$ соответственно.

3. На основании теории МГДО о перемещении в индуцируемом электрическом поле заряженных частиц можно утверждать, что в условиях эксперимента (температура $700{ }^{\circ} \mathrm{C}$, время охлаждения 3 мин) в алюминиевом сплаве $1417 \mathrm{M}$ происходит частичная ионизация атомов металлов, что дает возможность перемещать их в направлении вектора электрического поля.

4. МГДО позволяет значительно снизить энергозатраты при осуществлении процессов электропереноса в алюминиевых сплавах.

5. Проведена успешная апробация нового метода обработки металлических сплавов, осуществляющего электроперенос элементов внутри сплава и не требующего внедрения электродов в расплав и сооружения высоковольтных установок.

Работа выполнена в рамках проекта 16-43-242013 р_офи_м «Влияние индуцируемого электрического поля на ионы водорода в расплаве алюминиевого сплава» при поддержске ФБУ «Российский фонд фундаментальных исследований», правительства Красноярского края, Краевого государственного автономного учреждения «Красноярский краевой фонд поддержки научной и научно-технической деятельности». 


\section{Список литературы}

[1] Каблов Е.Н. Инновационные разработки ФГУП «ВИАМ» ГНЦ РФ по реализации Стратегических направлений развития материалов и технологий их переработки на период до 2030 г. Авиационные материалы и технологии, 2015, 1, 3-33 [Kabalov E.N. Innovative developments of FSUE VIAM of SSC RF on realization The strategic directions of development of materials and technologies of their processing for the period till 2030. Aviation materials and technologies, 2015, 1 (34), 3-33 (in Russian)].

[2] Каблов Е.Н., Щетанов Б.В., Гращенков Д.В., Шавнев А.А., Няфкин А.Н. Металлические композиционные материалы на основе Al-SiC. Авиационные материаль и технологии, 2012. № 5, 373-380 [Kablov E.N., Shchetanov B.V., Grashchenkov D.V., Shavnev A.A., Nyafkin A.N. Metal composites on the basis of Al-SiC. Aviation materials and technologies, 2012. No. 5, 373-380 (in Russian)].

[3] Каблов Е.Н., Старцев О.В., Медведев И.М. Обзор зарубежного опыта исследований коррозии и средств защиты от коррозии. Авиаиионные материаль и технологии, 2015, 2, 76-87 [Kablov E.N., Startsev O.V., Medvedev I.M. The review of foreign experience of researches of corrosion and means of protection from corrosion. Aviation materials and technologies, 2015, 2, 76-87 (in Russian)].

[4] Куценко А.А. Исследование влияния электрического тока на структурообразование и свойства высококачественных отливок, автореф. дис. ... канд. техн. наук. Новокузнецк, 2014, 18 с. [Kutsenko A.A. Research of influence of electric current on structurization and properties of high-quality mold pieces, Thesis ... cand. of tech. sci. Novokuznetsk, 2014, 18 p. (in Russian)].

[5] Тимченко С.Л., Кобелева Л.И., Задорожный Н.А. Влияние электрического тока на структуру и свойства алюминиевого сплава. Физика и химия обработки материалов, 2011, 6, 82-87. [Timchenko S.L., Kobeleva L.I., Zadorozhny N.A. Influence of electric current on structure and property of aluminum alloy. Physics and chemistry of processing of materials, 2011, 6, 82-87 (in Russian)].

[6] Epstein S.Y., Paskin A. Atom Motion in Liquid Aeolus in the Presence of an Elektric Field. Phys. Lett., 1967, V. 24A, 6, 309-310.

[7] Миненко Г.Н., Смирнова Ю.А. Физическая модель воздействия электрического тока на процесс кристаллизации сплава. Металлургия машиностроения, 2009, 3, 48-49. [Minenko G.N., Smirnov Yu.A. Physical analog of impact of electric current on alloy crystallization process. Mechanical engineering metallurgy, 2009, 3, 48-49 (in Russian)].

[8] Блатт Ф.Дж., Шредер П.А., Фойлз К.Л. и др. Термоэлектродвижущая сила металлов. М.: Металлургия, 1980. 248 с. [Blatt F.Jr., Schroder P.A., Foylz K.L., etc. Thermoelectric power of metals. M.: Metallurgy, 1980. 248 p. (in Russian)].

[9] Мальцева Ю.Ю. Разработка ресурсосберегающей технологии производства отливок из жаропрочных сплавов с использованием внутреннего электронагрева металла во время затвердевания, автореф. дис. ... канд. техн. наук. Рыбинск, 2006, 287 с. [Maltseva Yu.Yu. Development of the resource-saving production technology of mold pieces from high-temperature alloys with use of internal electroheating of metal in a setting time, Thesis ... cand. of tech. sci. Rybinsk, 2006, 287 p. (in Russian)]. 
[10]Fucheng, Zhang, Ming Zhang, Bo Li, Jianhui Li. Effect of high energy-density pulse current on solidification. Materials Science, 2007, 13(2), 120-123.

[11] Ахияров Р.Ж., Николаев О.А., Ибрагимов И.Г., Лаптев А.Б., Бугай Д.Е. Применение магнитогидродинамической обработки для удаления сульфат-ионов из пластовых сред. Проблемы сбора, подготовки и транспорта нефти и нефтепродуктов, 2008, 4, 41-47 [Akhiyarov R.Zh., Nikolaev O.A., Ibragimov I.G., Laptev A.B., Bugay D.E. Application of magneto-hydrodynamic processing for removal sulfate ions from sheeted environments. Problems of collecting, preparation and transport of naphtha and oil products, 2008, 4, 41-47 (in Russian)].

[12]Ахияров Р.Ж., Рахимов С.Р., Матвеев Ю.Г., Лаптев А.Б., Бугай Д.Е., Латыпов О.Р. Методика расчета параметров магнитогидродинамической обработки для подготовки нефти на промыслах. Нефтегазовое дело: электрон. науч. журн., 2011, 5, 342-351 [Akhiyarov R.Zh., Rakhimov S.R., Matveev Yu.G., Laptev A.B., Bugay D.E., Latypov O.R. A method of calculation of parameters of magneto-hydrodynamic processing for preparation of naphtha on crafts. Oil and gas business: online scientific journal, 2011, 5, 342-351. (in Russian)].

[13]Способ обработки потока технологической жидкости и устройство для его осуществления. пат. 2287492 Рос. Федерация, № 2005128408/15; заявл. 01.09.2005; опубл. 20.11.2006, Бюл. № 32. [Way of processing of a stream of technological liquid and the device for its exercise. Patent № 2287492, Russian Federation (in Russian)].

[14]Способобработкикоррозионнойсреды.пат.№2293707,Рос. Федерация,№2005128408/15; заявл. 01.09.2005; опубл. 20.02.2007, Бюл. № 3. [Way of processing of the corrosion environment. Patent № 2293707, Russian Federation (in Russian)].

[15]Luck W.A.P., Klein D., Rangsriwatananon K. Anti-cooperativity of the two water OH groups. J. Mol. Struct., 1997, 416, 287-296.

[16]Устройство для магнитной обработки жидкости. Патент 54035 на полезную модель. № 2005136584/22 Рос. Федерация заявл. 24.11.2005. Опубл. 10.06.2006 Бюл. № 16 [The device for magnetic processing of liquid. Patent № 54035, Russian Federation (in Russian)]. 